\title{
COMPARISON OF USING RELATIVE AND ABSOLUTE PCV CORRECTIONS IN SHORT BASELINE GNSS OBSERVATION PROCESSING
}

\author{
Karol Dawidowicz \\ University of Warmia and Mazury \\ Institute of Geodesy \\ ul. Oczapowskiego 1, 10-950 Olsztyn, Poland \\ e-mail: karol.dawidowicz@uwm.edu.pl
}

\begin{abstract}
GNSS antenna phase center variations (PCV) are defined as shifts in positions depending on the observed elevation angle and azimuth to the satellite. When identical antennae are used in relative measurement the phase center variations will cancel out, particularly over short baselines. When different antennae are used, even on short baselines, ignoring these phase center variations can lead to serious (up to $10 \mathrm{~cm}$ ) vertical errors. The only way to avoid these errors, when mixing different antenna types, is by applying antenna phase center variation models in processing.

Till the 6th November 2006, the International GNSS Service used relative phase center models for GNSS antenna receivers. Then absolute calibration models, developed by the company "Geo++", started to be used. These models involved significant differences on the scale of GNSS networks compared to the VLBI and SLR measurements. The differences were due to the lack of the GNSS satellite antenna calibration models. When this problem was sufficiently resolved, the IGS decided to switch from relative to absolute models for both satellites and receivers. This decision caused significant variations to the results of the GNSS network solutions.

The aim of this paper is to study the height differences in short baseline GNSS observations processing when different calibration models are used. The analysis was done using GNSS data collected at short baselines moved with different receiver antennas. The results of calculations show, that switching from relative to absolute receiver antenna PCV models has a significant effect on GNSS network solutions, particularly in high accuracy applications.
\end{abstract}

Keywords: GNSS antenna, phase center variations, GNSS data processing.

\section{INTRODUCTION}

The actual antenna phase center is the point in space where the GNSS signal is received. That point varies depending on the direction of the incoming GNSS signal, i.e. on the observed elevation angle and azimuth to the satellite. For practical purposes, the mean position of the electrical antenna phase center (MPC) is determined. The antenna height above the physical network point is measured to the antenna reference point (ARP). The IGS has defined the ARP as the intersection of antenna's vertical axis of symmetry with the bottom of the antenna. The antenna phase center offset (PCO) is the difference between the ARP and the MPC. 
A deviation arises when comparing the actual antenna phase center of an individual measurement with the MPC. These deviations are defined as antenna phase center variations (PCV). A review of the antenna phase center variations problem can be found e.g. in Braun et al. (1993), Geiger (1998), Hofmann-Wellenhof et al. (2008), Rocken (1992), Schmid et al. (2005), Schmitz et al. (2002), Schupler and Clark (1991), Wanninger (2009).

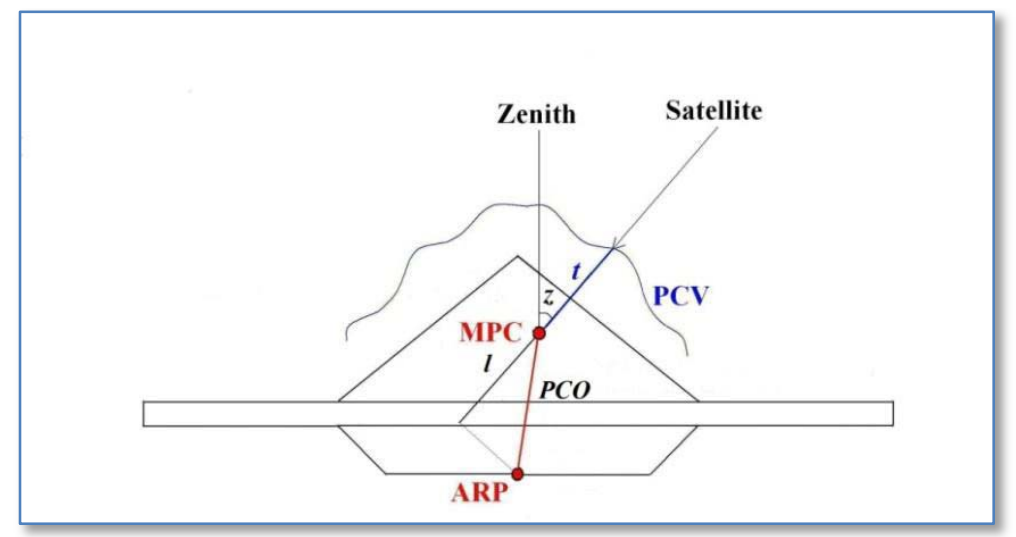

Fig. 1. Main receiver antenna points and theirs spatial relations (source: own work based on Schmid et al., 2005)

Antenna phase center variations can have an amplitude of several centimeters. When identical antennae are used in relative measurement, the phase center variations will cancel out, particularly over short baselines. When different antennae are used, even on short baselines, ignoring these phase center variations can lead to serious (up to $10 \mathrm{~cm}$ ) vertical errors (Rothacher and Mader, 1996; Mader, 1999).

Relations between ARP, MPC and PCV points (Fig. 1) can be determined through the calibration process. As a result, the antenna phase center corrections (PCC) are created. Antenna PCC are given by (Dach et al., 2007):

where: $\quad$ - total phase center corrections in direction - azimuth and - zenith angle, $P C O$ - position of the MPC with respect to the mechanically defined ARP, $e$ - the unit vector in the direction from the receiver ARP to satellite, - the spherical harmonic function of the phase center variations.

Three methods are currently used to determine GNSS receiver antenna phase center variations:

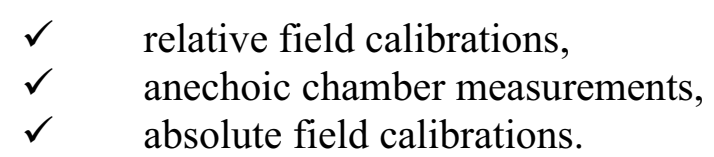

Relative field calibration is a procedure where the PCV of one antenna is determined with respect to another, a reference antenna (Mader, 1999; Rothacher and Mader, 1996). In this way, only the differences in the phase center behavior between the two antennas may be computed. This method is based on the assumption that the reference antenna (Alan Osborne AOAD/M_T) had zero PCV and offsets are defined as L1 $=11 \mathrm{~cm}, \mathrm{~L} 2=12.8 \mathrm{~cm}$.

The drawbacks of the relative calibration method are:

- the antenna PCV'-s were estimated with a $10^{\circ}$ cut of angle,

- the PCO'-s and PCV'-s of the reference antenna are known for their low accuracy,

- the lack of azimuth angles in the antenna PCV'-s estimation.

These deficiencies were the reason that the absolute antenna calibration method was developed. 
In anechoic chamber measurements of an absolute antenna PCV are obtained by measuring how the phase of an artificial GPS signal is changed when the antenna (put into an anechoic chamber) is rotated and tilted. The advantage of the laboratory procedure is achieving constant environments for all calibrated antennas and its very high efficiency (40-60 min). The main disadvantage is that the test signal differs from the real GNSS signal. Absolute field calibrations are performed using a high precision robot and two antennas. The robot rotates and tilts the antenna while the reference antenna is kept fixed. The advantages of the absolute field calibration are, that the real GNSS signals are tracked with a real receiver and the antenna is in the natural field environment. In contrast to the relative antenna calibrations, the robot measurements allow the determination of patterns to zero degree elevation and allow elimination of multipath effects to a large extent (Falko et al., 1998; Rothacher, 2001; Wübbena et al., 1997).

Despite the advantages of the absolute methods, the IGS did not decide to accept these methods as the official antenna calibration methods until 2006. The main reason was that the use of absolute antenna PCC caused an unreasonable scale error (15 ppb) and as results a height change of 5 to $10 \mathrm{~cm}$. Many experiments were held in order to understand the source that introduces this scale error (Rothacher, 2001; Schmidt and Rothacher, 2003; Zhu et al., 2003). Finally, the researchers realized that not only the receiver, but also the satellite antenna shows phase center variations. These variations were the reason for the scale factor that results in global GNSS solutions, when absolute phase center patterns are applied.

The precise ephemeris provides the satellite coordinates of the mass centre of the satellite while the geometrical distance between satellite and receiver refers to their electrical phase centre. The distance $d z$ (Fig. 2) between the satellite antenna electrical phase centre and satellite centre of mass should be well-known, otherwise, an error $d r$ of the geometrical distance may occur, given by:

where: $b$ - the angle between satellite-earth centre and satellite-receiver directions.

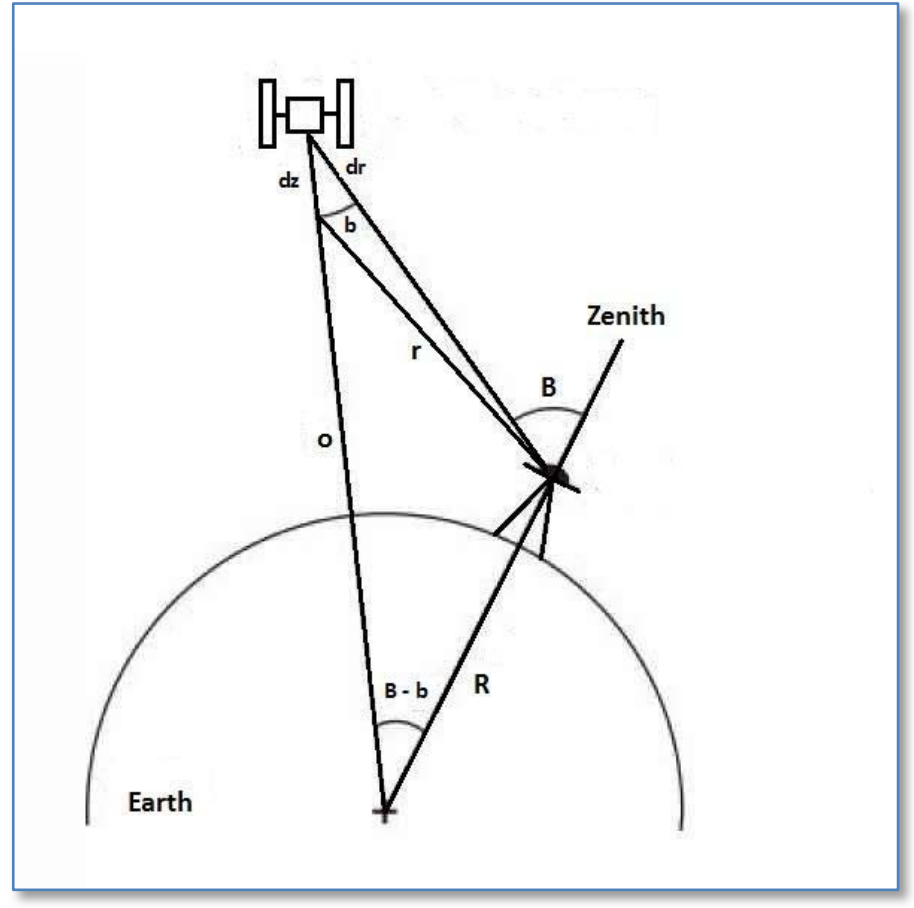

Fig. 2. Satellite PCO problem

(source: own work based on Zhu at al., 2003) 
Before satellite antenna calibrations, only one offset value was known for each of the satellite blocks and it was not even clear whether these offsets denote the phase center of the L1 or L2 frequency.

The estimation of the satellite antenna PCO and PCV was made by GeoForschungsZentrum (GFZ) and the Technical University of Munich (TUM). It was decided that only z-offsets and the PCV with respect to the elevation angle would be estimated. Because the differences between antenna PCV of the satellites from the same block were almost zero, the PCV were estimated for each satellite block. However, PCO was estimated for each satellite antenna. The final antenna phase center corrections were the average of those two solutions (Schmid et al., 2007).

This paper presents a study of the height differences in GNSS observations processing when different calibration models are used. The analysis was done using GNSS data collected at short baselines moved with different receiver antennas.

\section{METHODOLOGY OF STUDIES}

At present, there are three models of receiver antennas and two GNSS satellites in use. For receiver antennas, there are:

- relative IGS antenna phase center correction model (from relative field calibration),

- absolute IGS antenna phase center correction model (converted from relative - all the relative antenna offsets and phase center variations that the National Geodetic Survey has computed have been added to the absolute values for AOAD/M_T antenna),

- absolute IGS antenna phase center correction model (from absolute field calibration).

For GNSS satellites there may be two solutions:

- standard IGS antenna offset model,

- absolute antenna phase center correction model.

For the purposes of analysis some commercial post-processing software in the context of PCV problem reduction was verified. In Ashtech Solutions 1.0 there is no model or algorithm for reduction receiver antenna PCO or PCV (Magellan..., 1998). In Ashtech Solutions 2.0 there is only the possibility to reduce the receiver antenna PCO, but not the antenna PCV (Thales... 2002). Only the newest versions of commercial software have the ability to correct receiver antenna PCV. An example is GNSS Solutions, in which the receiver antennas PCO from relative field calibrations are placed and it is possible to edit these values and add elevationdependent PCV (Magellan..., 2008). In Topcon Tools from version 6.11, the absolute receiver antenna calibration models (converted from relative) are applied by default (Topcon..., 2006). For GNSS satellites, all commercial software probably use the standard IGS antenna offsets.

Because in most commercial post-processing software the solution of the antenna phase center variation problem is simplified and, additionally, there is often no information about any models or algorithms used to reduce that error, a special subroutine was developed for the purposes of analysis.

A proprietary subroutine corrects observations using information about the real position of the antenna phase center which is a function of GNSS signal direction. This information is available, for example, on the International GNSS Service website in ANTEX format text files. In ANTEX files, the antenna profiles are defined by three so-called offsets ("north", "east" and "up") and changes of the antenna phase center position as a function of incoming signal elevation and also (at present for some antennas) as a function of azimuth. These values are given in a five-degree interval: from $0^{\circ}$ to $80^{\circ}\left(90^{\circ}\right)$ for elevation and from $0^{\circ}$ to $360^{\circ}$ for azimuth.

The developed subroutine, written in the MATLAB programming language, introduces (Fig. 3) corrections to code and phase observations based on ANTEX and RINEX 
observation and navigation files. Several processing steps have to be performed in order to implement PCV corrections to GNSS observations:

1) The satellites' coordinates on each observational epoch are calculated.

2) The elevation and azimuth of satellites at the same observational epoch are calculated using the satellites' positions and approximate coordinates of the receiver.

3) The next stage is reading the proper data from ANTEX file. These values are then used to calculate the corrections to code and phase observations.

4) Calculation of corrected observations.

The subroutine allows observation corrections using antenna calibration results from all centers where they are created. The observations can be reduced to MPC or to ARP.

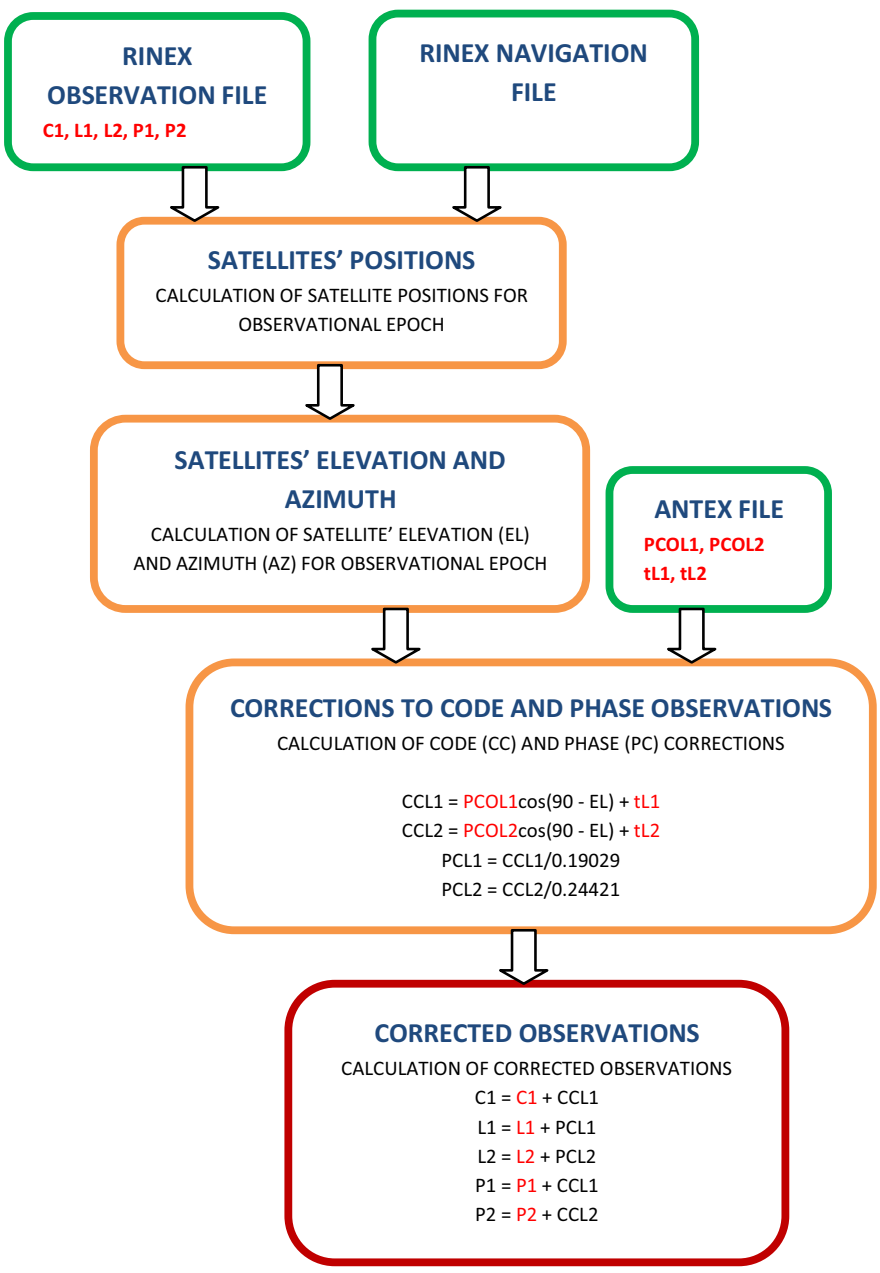

Fig. 3. Implementing the PCV corrections to the RINEX observations file

Because the phase center variation $(t)$ is expressed in ANTEX file in five degrees interval, its exact value (for actual elevation or elevation and azimuth) is calculated by a well-known linear interpolation formula.

The correctness of the subroutine has been tested, e.g. in Dawidowicz (2010).

The aim of this paper is to study the height differences in GNSS observations processing when different calibration models are used. The analysis was done using GNSS observations collected at short baselines moved with different receiver antennas. Such type of data is usually processed on L1 frequency in short observation sessions.

The measurements were done on a test network consisting of three points (Fig. 4). The longest measured vector has about $1.8 \mathrm{~km}$ and the shortest is about $0.6 \mathrm{~km}$. On the test points, a 24-hour measurement session was conducted. The following GPS parameters were assumed 
for the session: sampling interval $5 \mathrm{~s}$, minimum satellite' elevation $5^{\circ}$. As a reference, the point with the ASH701945C_M antenna was chosen.

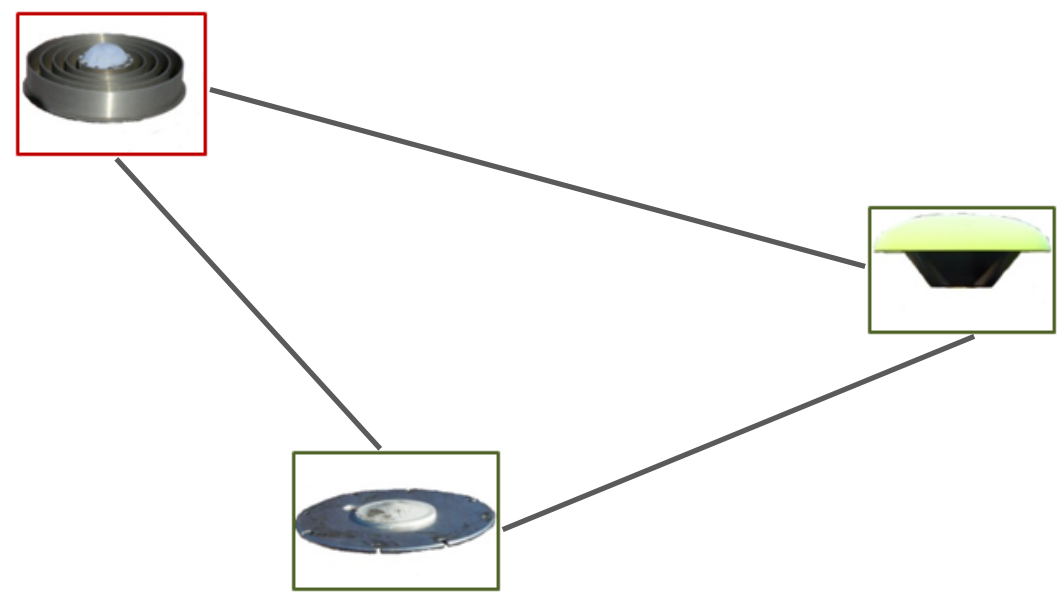

Fig. 4. The test network

Three types of antenna, presented in Figure 5, were used in the measurements: ASH701945C_M, ASH700718A and JAV_GRANT-G3T.

a)

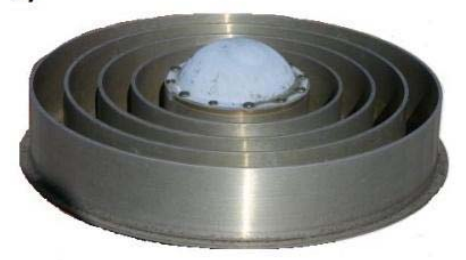

b)

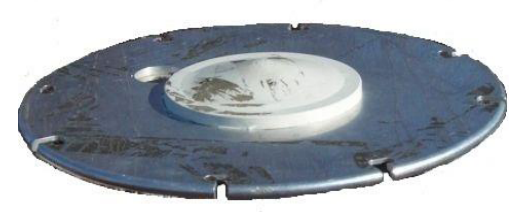

c)

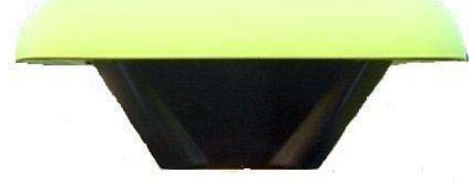

Fig. 5. Antennas used in measurements: a) ASH701945C_M, b) ASH700718A, c)

$$
\text { JAV_GRANT-G3T }
$$

The locations of MPC over ARP ("up" offset) for L1 and L2 frequencies for these antennas obtained from different calibration methods are presented in Table 1.

Table 1. The locations of MPC over ARP for antennas used in measurements

\begin{tabular}{|c|c|c|c|c|c|c|}
\hline \multirow{2}{*}{ Calibration model } & \multicolumn{5}{|c|}{ Locations of MPC over ARP [mm] } \\
\cline { 2 - 7 } & \multicolumn{2}{|c|}{ ASH701945C_M } & \multicolumn{2}{c|}{ ASH700718A } & JAV_GRANT-G3T \\
\cline { 2 - 7 } & L1 & L2 & L1 & L2 & L1 & L2 \\
\hline Relative IGS & 109.3 & 126.2 & 83.9 & 62.3 & 69.4 & 60.6 \\
\hline Absolute IGS converted & 90.5 & 118.3 & 65.1 & 54.4 & 50.6 & 52.7 \\
\hline Absolute IGS & 89.87 & 119.49 & 68.54 & 55.46 & 50.28 & 46.83 \\
\hline
\end{tabular}

Figures 6,7 and 8 presents comparison of the relative and absolute elevation dependent phase center variations for antennas used in measurements. A comparison was made in antenna pairs (antenna fixed point and antenna unknown point) - it is clear that the selected antennas have different profiles. 

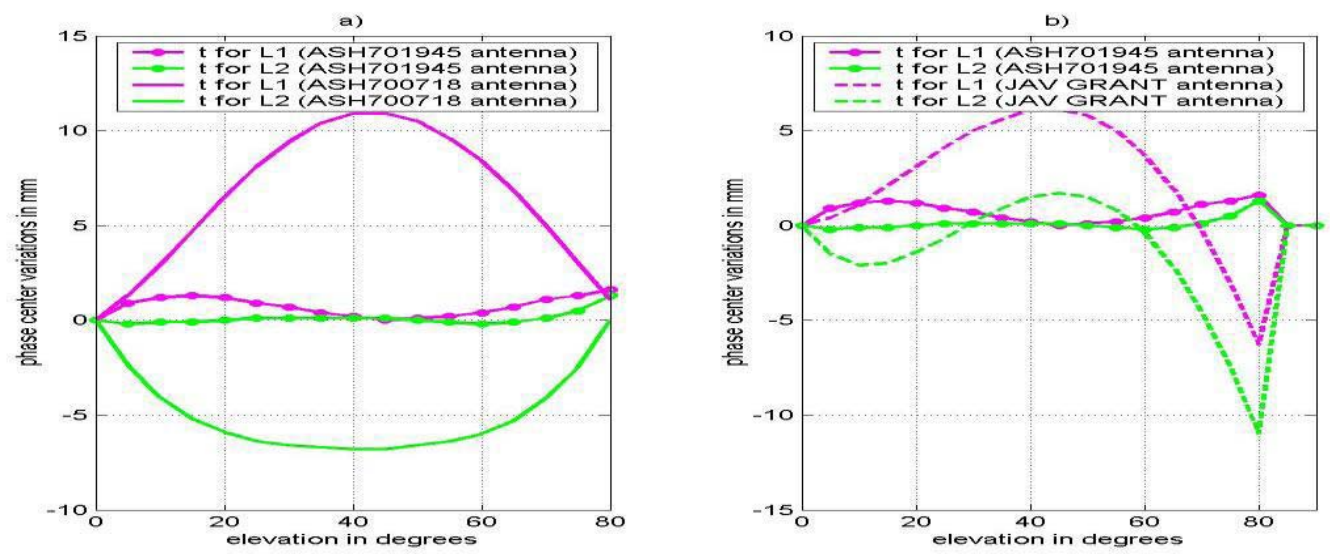

Fig. 6. IGS relative elevation dependent phase center variations: a) for antenna pair ASH701945C_M and ASH700718A; b) for antenna pair ASH701945C_M and JAV_GRANT-G3T.
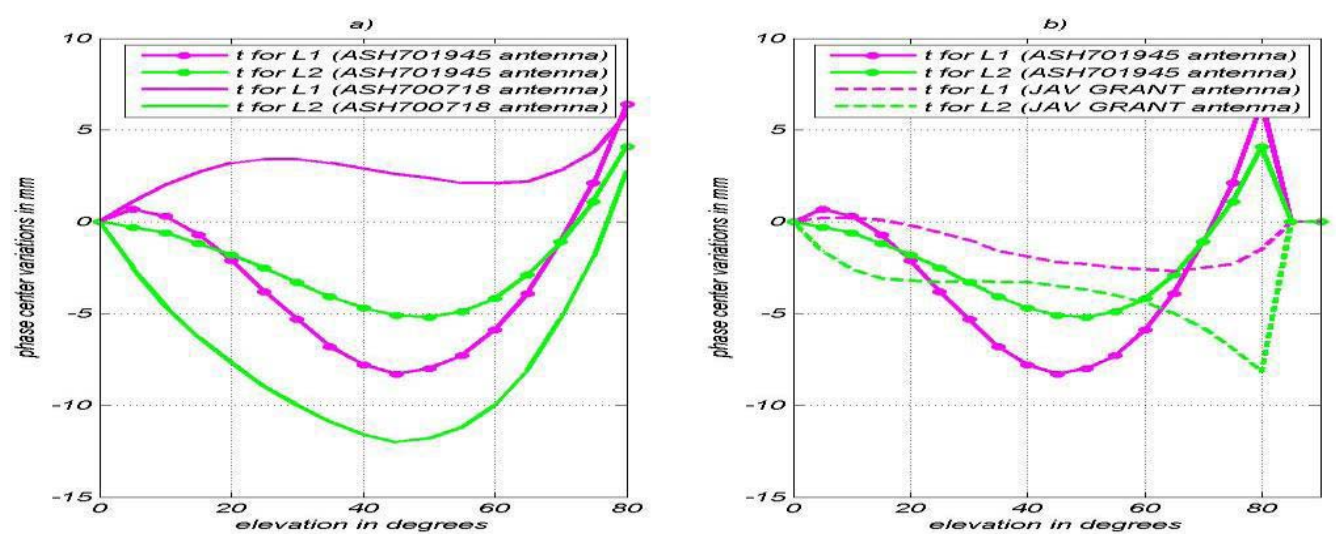

Fig. 7. IGS absolute (converted from relative) elevation dependent phase center variations: a) for antenna pair ASH701945C_M and ASH700718A; b) for antenna pair ASH701945C_M and JAV_GRANT-G3T.
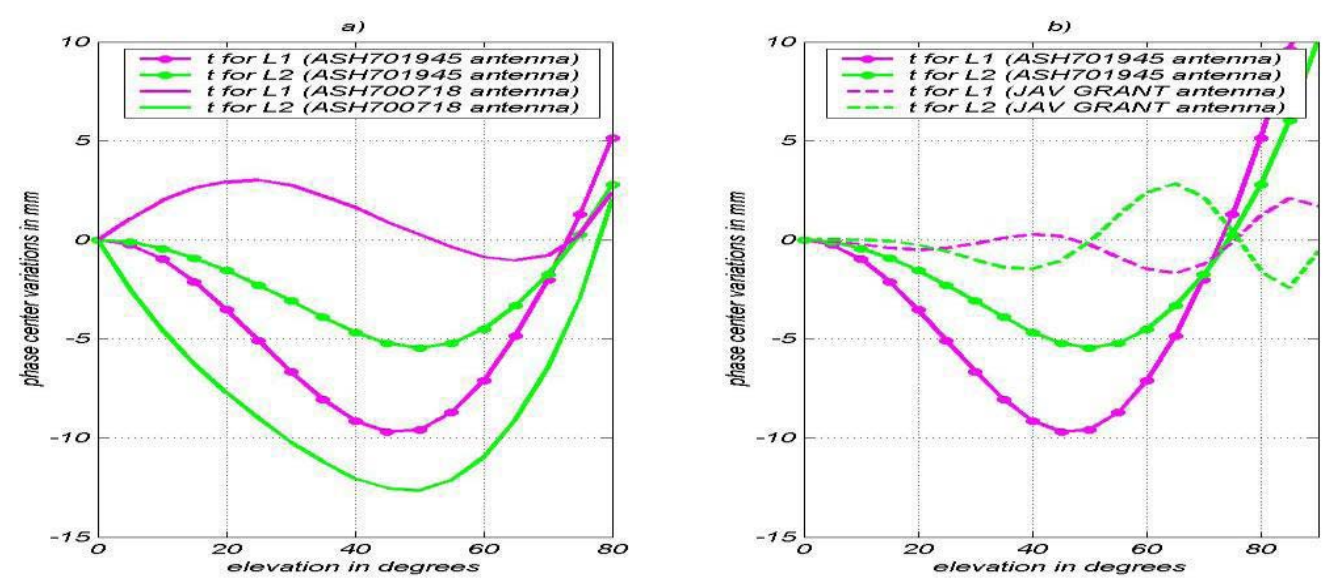

Fig. 8. IGS absolute (from absolute field calibration) elevation dependent phase center variations: a) for antenna pair ASH701945C_M and ASH700718A; b) for antenna pair ASH701945C_M and JAV_GRANT-G3T. 
Because the measurement was performed on baselines, whose length does not exceed $2 \mathrm{~km}$, the analysis focused only the study of height differences when different receiver antenna calibration models are used in GNSS observation processing. The study (Chatazinikos et al., 2009), as expected, shows that the effect of the satellite antenna phase center corrections on the local network solutions is below $1 \mathrm{~mm}$.

The GNSS observations for all points were corrected by a proposed subroutine with the use of the three above-described antenna PCV models. Relative and absolute-converted models contains values of elevation dependent antenna phase center variations. The absolute model contains, for most of the antennas, values of elevation and azimuth dependent antenna phase center variations. Post-processing was done in four variants:

- processing observations without PCV corrections,

- processing observations using three PCV models.

To processing, GNSS Solutions software was used. As a reference point, the station with the ASH701945C_M antenna was chosen. Analyses were done using GNSS data collected at short baselines. For analysis, 24-hour sessions were divided into 30- and 15-minute sessions.

\section{RESULTS AND ANALYSIS}

Figures 9-12 illustrate the 30- and 15-minute time series of heights obtained from four processing variants. Because the height point differences between the solutions using relative and absolute (converted from relative) IGS antenna phase center corrections models, as expected, equaled zero (a $1 \mathrm{~mm}$ difference was achieved for only a few sessions), these two solutions can be considered identical. For this reason, figures 9-12 present only the results obtained using relative and absolute IGS antenna phase center correction models.

Part a of each figure presents the variations of height derived from 30- or 15-minute GPS session processing. Additionally, the mean heights (with solid lines) and the heights obtained from 24-hour solutions (with dotted lines) are shown. Part $\mathbf{b}$ of the figures present the height differences between solutions using appropriate PCV models and solutions without PCV corrections.

The results of 48 sessions of static positioning for the ASH700718 antenna in 30-min sessions are presented in figure 9. In figure 10, the results of 96 sessions for the same antenna in 15-min sessions are shown.
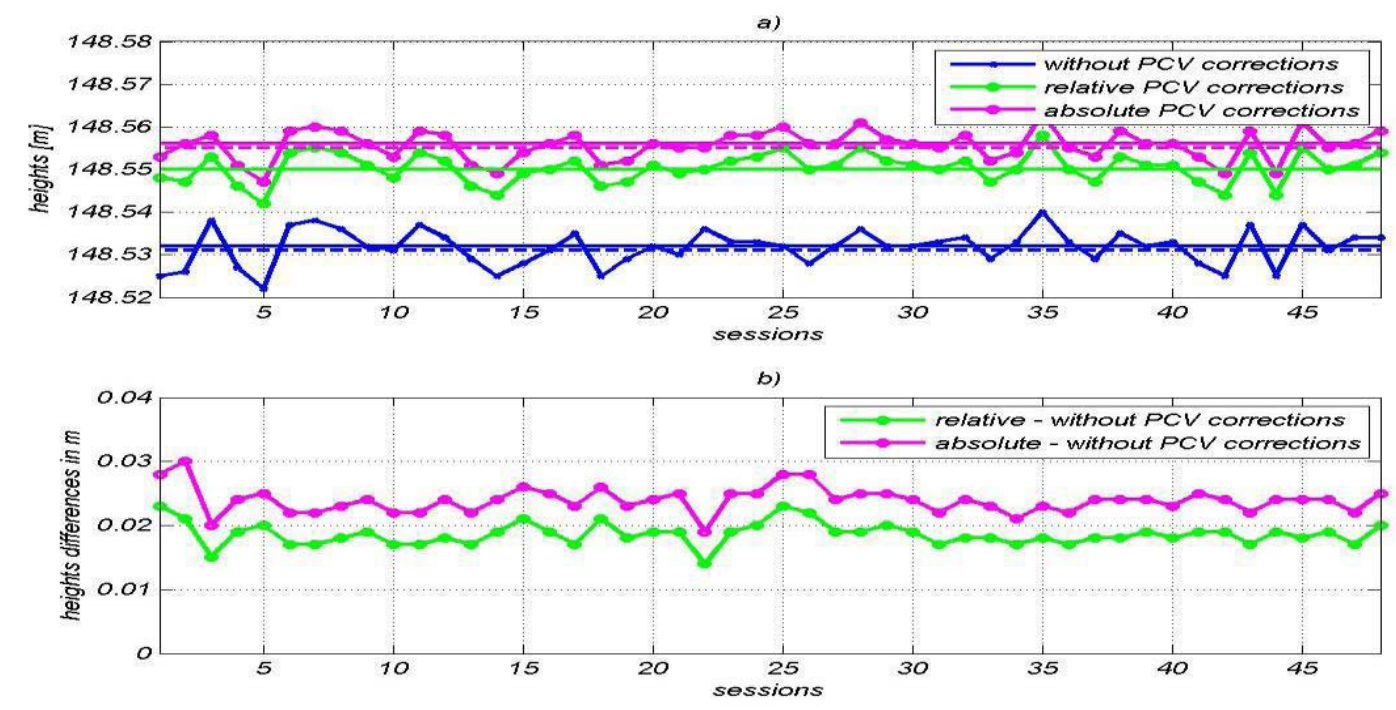

Fig. 9. The results of processing 30-min sessions for the ASH700718 antenna: a) height of point, b) height differences 

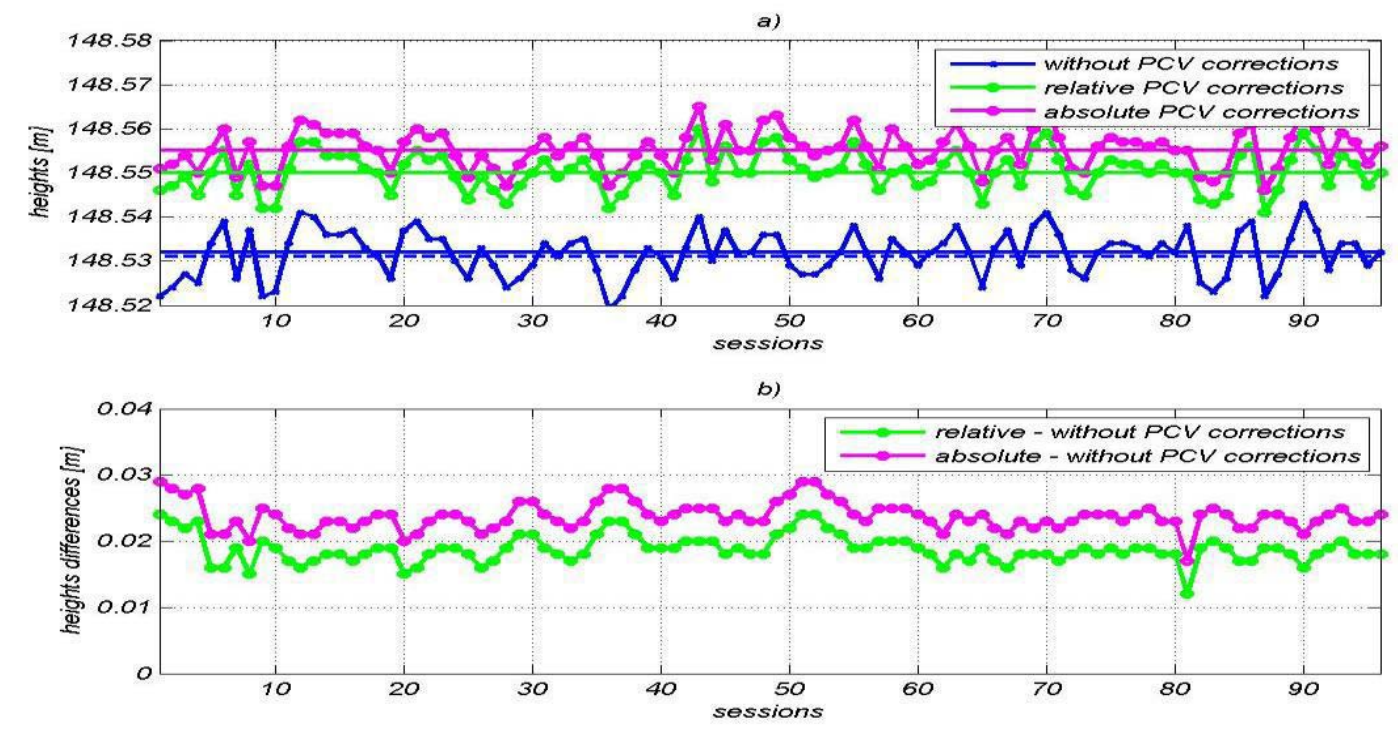

Fig. 10. The results of processing 15-min sessions for the ASH700718 antenna: a) height of point, b) heights differences

The maximum height variations and standard deviations obtained for point with the ASH700718 antenna from different post-processing variants are shown in Table 2. Table 3 shows a summary of the height differences obtained for the same point.

Table 2. Summary of height variations obtained for point with the ASH700718 antenna

\begin{tabular}{|c|c|c|}
\hline Post-processing variant & $\begin{array}{c}\text { Max. height } \\
\text { variations [cm] }\end{array}$ & $\begin{array}{c}\text { Standard } \\
\text { deviation [cm] }\end{array}$ \\
\hline 30-min sessions without PCV model & 1.8 & 0.40 \\
\hline 30-min sessions with relative PCV model & 1.6 & 0.35 \\
\hline 30-min sessions with absolute PCV model & 1.4 & 0.35 \\
\hline 15-min sessions without PCV model & 2.4 & 0.52 \\
\hline 15-min sessions with relative PCV model & 1.9 & 0.43 \\
\hline 15-min sessions with absolute PCV model & 1.7 & 0.43 \\
\hline
\end{tabular}

Table 3. Summary of height differences obtained for point with the ASH700718 antenna

\begin{tabular}{|c|c|c|c|c|}
\hline Post-processing variants & \multicolumn{2}{|c|}{ 30-min sessions } & \multicolumn{2}{c|}{ 15-min sessions } \\
\cline { 2 - 5 } & $\begin{array}{c}\text { Max. height } \\
\text { difference [cm] }\end{array}$ & $\begin{array}{c}\text { Min. height } \\
\text { difference [cm] }\end{array}$ & $\begin{array}{c}\text { Max. height } \\
\text { difference [cm] }\end{array}$ & $\begin{array}{c}\text { Min. height } \\
\text { difference [cm] }\end{array}$ \\
\hline $\begin{array}{c}\text { with relative PCV model } \\
\text { and without PCV model }\end{array}$ & 2.3 & 1.4 & 2.4 & 1.5 \\
\hline $\begin{array}{c}\text { with absolute PCV model } \\
\text { and without PCV model }\end{array}$ & 2.8 & 1.9 & 2.9 & 2.0 \\
\hline
\end{tabular}

In figures 9 and 10, it can be seen that between solutions with absolute and relative PCV models there is a systematic $0.5 \mathrm{~cm}$ difference. This difference should be treated as a result of the transition from a relative to absolute PCV model for the ASH700718 antenna. It is also clear that the courses of height variations from 30-min and 15-min sessions solution are very similar.

In comparing the maximum height variations and standard deviation (Table 2), it is clear that their size increases with a shortening of session time and is reduced for the variants with PCV models. 
The results of 48 sessions of static positioning for the JAV_GRANT-G3T antenna in 30min sessions are presented in figure 11. In figure 12, the results of 96 sessions for the same antenna in 15-min sessions are shown.
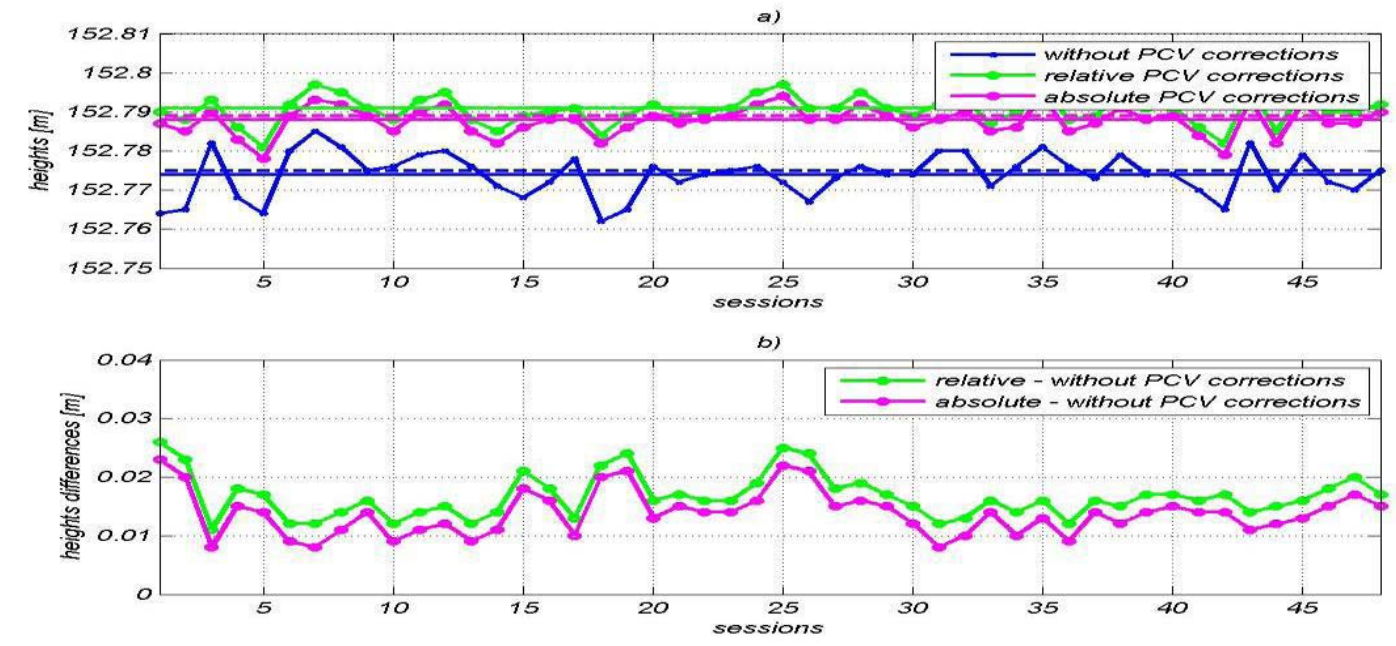

Fig. 11. The results of processing 30-min sessions for the JAV_GRANT-G3T antenna: a) height of point, b) height differences
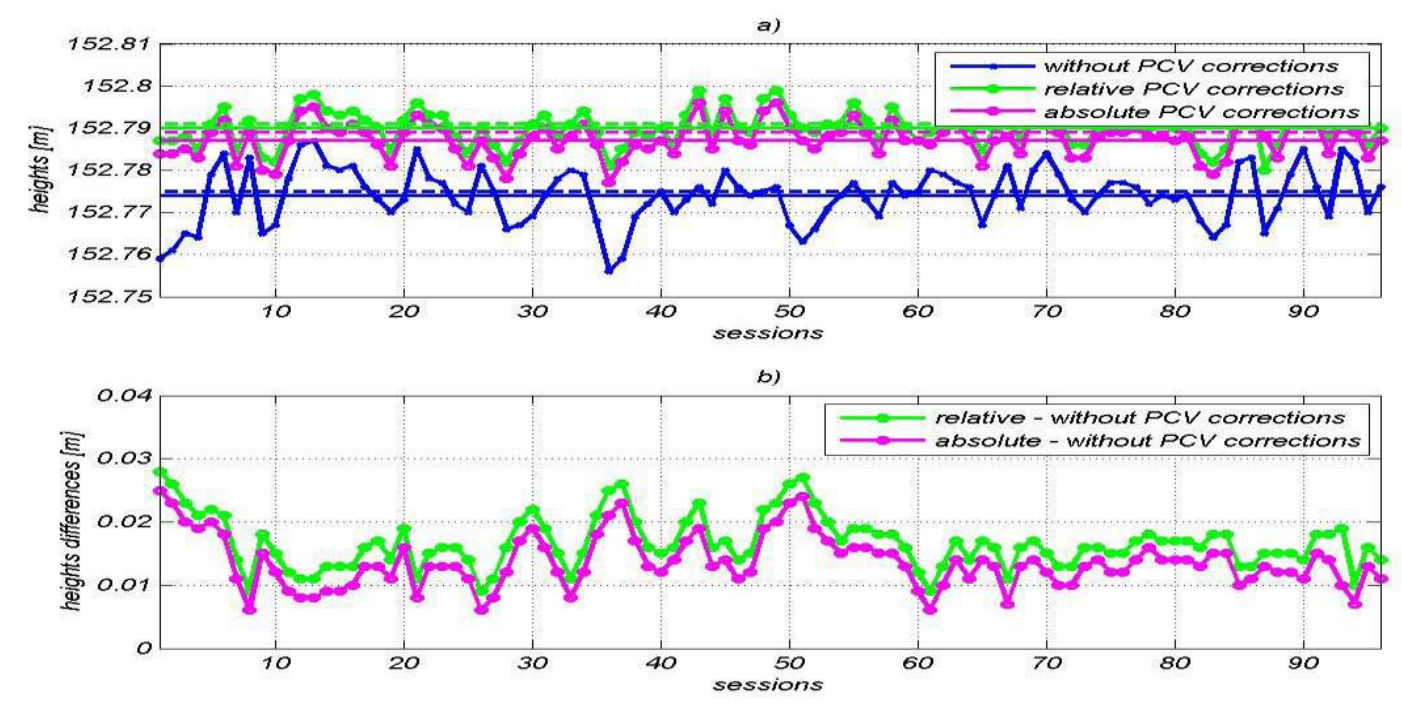

Fig. 12. The results of processing 15-min sessions for the JAV_GRANT-G3T antenna: a) height of point, b) height differences

The maximum height variations and standard deviations obtained for point with the JAV_GRANT-G3T antenna from different post-processing variants are shown in Table 4. Table 5 shows a summary of the height differences obtained for the same point.

Table 4. Summary of height variations obtained for point with the JAV_GRANT-G3T

\begin{tabular}{|c|c|c|}
\hline Post-processing variant & $\begin{array}{c}\text { Max. height } \\
\text { variations [cm] }\end{array}$ & $\begin{array}{c}\text { Standard } \\
\text { deviation }[\mathrm{cm}]\end{array}$ \\
\hline 30-min sessions without PCV model & 2.0 & 0.55 \\
\hline 30-min sessions with relative PCV model & 1.6 & 0.37 \\
\hline 30-min sessions with absolute PCV model & 1.6 & 0.36 \\
\hline 15-min sessions without PCV model & 3.1 & 0.63 \\
\hline 15-min sessions with relative PCV model & 1.9 & 0.44 \\
\hline 15-min sessions with absolute PCV model & 1.9 & 0.43 \\
\hline
\end{tabular}


Table 5. Summary of height differences obtained for point with JAV GRANT-G3T antenna

\begin{tabular}{|c|c|c|c|c|}
\hline Post-processing variants & \multicolumn{2}{|c|}{ 30-min sessions } & \multicolumn{2}{c|}{ 15-min sessions } \\
\cline { 2 - 5 } & $\begin{array}{c}\text { Max. height } \\
\text { difference [cm] }\end{array}$ & $\begin{array}{c}\text { Min. height } \\
\text { difference [cm] }\end{array}$ & $\begin{array}{c}\text { Max. height } \\
\text { difference [cm] }\end{array}$ & $\begin{array}{c}\text { Min. height } \\
\text { difference [cm] }\end{array}$ \\
\hline $\begin{array}{c}\text { with relative PCV model } \\
\text { and without PCV model }\end{array}$ & 2.6 & 1.1 & 2.8 & 0.9 \\
\hline $\begin{array}{c}\text { with absolute PCV model } \\
\text { and without PCV model }\end{array}$ & 2.3 & 0.8 & 2.5 & 0.6 \\
\hline
\end{tabular}

Figures 11 and 12 show that between solutions with absolute and relative PCV models there is a systematic $-0.3 \mathrm{~cm}$ difference. This difference is the result of the transition from relative to absolute PCV model for the JAV_GRANT-G3T antenna. As for the ASH700718 antenna, it is also clear that the course of height variations from 30-min and 15-min sessions solutions are similar.

By comparing the maximum height variations and standard deviation (Table 4), it is also apparent that their size increases with a shortening of session time and is reduced for the variants with PCV models.

\section{CONCLUSIONS}

In this study, the heights obtained from short baseline GNSS observations processed using different PCV models are compared. Analyses were done using 24-hour GNSS data divided into 30- and 15-minutes sessions.

Such short sessions seem to be insufficient for accurate determination of heights. The maximum height variations derived from 30- or 15-minute GPS sessions processing is approximately $2-3 \mathrm{~cm}$.

Processing GNSS observations without PCV corrections gave, for the selected antennas, an height determination error reaching a maximum value of about $3 \mathrm{~cm}$ (heights differences obtained from comparing the results of observations processed both with and without PCV models). Clearly visible changes in these differences can be treated as a result of changes in the satellites' constellation above the point of measurement.

Switching from relative to absolute receiver antenna PCV models has a visible effect on GNSS network solutions, particularly in high-accuracy applications. The height differences, caused by switching from relative to absolute PCV models for the three pairs of antennas used in the measurements were from $0.3 \mathrm{~cm}$ (ASH701945C_M and JAV_GRANT-G3T) to $0.8 \mathrm{~cm}$ (ASH700718 and JAV_GRANT-G3T).

\section{REFERENCES}

Braun J., Rocken C., Meertens C.M., Johanson J. (1993). GPS antenna mixing and phase center corrections. Eos Trans. AGU, Fall Meeting Supplement, p. 197.

Chatazinikos M., Fotiou A., Pikradis C. (2009). The effects of the receiver and satellite antenna phase center models on local and regional GPS networks. Proceedings of the International Symposium "Modern technologies, educations and professional practice in geodesy and relative fields". Sofia, 5-6 November.

Dach R., Hugentobler U., Fridez P., Meindl M. (2007). Bernese GPS Software Version 5.0. Astronomical Institute, University of Bern, p. 327-346. 
Dawidowicz K. (2010). Antenna phase center variations corrections in processing of GPS observations with use of commercial software. Technical Sciences No 13, Y 2010, p. 120132.

Falko M., Seeber G., VölksenCh., Wübbena G., Schmitz M. (1998). Results of Absolute Field Calibration of GPS Antenna PCV. ION GPS-98; Proceedings of the 11th International Technical Meeting of the Satellite Division of the Institute of Navigation, Nashville, TN; UNITED STATES; 15-18 Sept. p. 31-38.

Geo++ GmbH / GeoService GmbH /. (2008). Format of Geo++ PCV Antenna File, http://www.geopp.de/media/docs/pdf/

Geiger A. (1998). Modeling of Phase Center Variation and its Influence on GPS Positioning. GPS-Techniques Applied to Geodesy and Surveying: Proceedings of the International GPS-Workshop Darmstadt, April 10 to 13, Editor: Erwin Groten, Robert Strauß, Lecture Notes in Earth Sciences, vol. 19, p. 210-222

Góral W., Kudrys J. (2007). Obliczanie poprawek uwzględniających wpływ charakterystyk anten w pomiarach fazowych GPS. Geomatics and Enviromental Engineering, Volume 1, Number 1/1, p. 133-139.

Hofmann-Wellenhof B., Lichtenegger H., Wasle E. (2008). GNSS - Global Navigation Satellite Systems, Springer-Verlag Wien, Austria.

IGS Working Group. (2008). IGS antenna files. ftp://igscb.jpl.nasa.gov/pub/station/genereal/ antenna_README.pdf

Mader G. L. (1999). GPS Antenna Calibration at the National Geodetic Survey. Journal of Geodesy, Volume 3, Number 1/July.

Magellan Corporation Ashtech Precision Products. (1998). Ashtech Solutions Tutorial. Printed in USA.

Magellan Navigation Inc. (2008). GNSS Solutions Reference Manual. Printed in USA.

Rothacher M. (2001). Comparison of Absolute and Relative Antenna Phase Center Variations. GPS Solutions vol. 4, No. 4, p. 55-60

Rothacher M., Mader G. (1996). Combination of antenna phase center offsets and variation: antenna calibration set IGS_01, anonymous ftp ubeclu.unibe.ch, June.

Rocken C. (1992). GPS antenna mixing problems. UNAVACO Memo, November 12.

Schupler B., Clark T. A. (1991). How different antennas affect The GPS observables. GPS World November/December.

Schmid R., Rotchaher M. (2003). Estimation of elevation-dependent satellite antenna phase center variations of GPS satellites. Journal of Geodesy, Vol. 77, p. 440-446.

Schmid R., Rothacher M., Thaller D., Steigenberger P. (2005). Absolute phase center corrections of satellite and receiver antennas. GPS Solutions, Volume 9, Number 4, November.

Schmid R., Steingerberg P., Rotchacher M. (2005). Benefits from absolute GPS antenna phase center modeling. Advances in GPS Data Processing and Modelling, London 9-10 November (www.espace-tum.de/mediadb/15354/15355/Vortrag_London.pdf).

Schmid R., Steingerberg P., Gendt G., Ge M., Rotchacher M. (2007). Generation of a consistent absolute phase center corrections model for GPS receiver and satellite antennas. Journal of Geodesy, Vol. 81, p. 781-798. 
Schmitz M., Wübbena G., Boettcher G. (2002). Tests of phase center variations of various GPS antennas, and some results. GPS Solutions, no 6, p. 18-27.

Thales Navigation. (2002). Ashtech Solutions User's Guide. Printed in USA.

Topcon Positioning System. (2006). Topcon Tools User's Guide. Topcon Positioning Systems Inc, May.

Wanninger L. (2009). Correction of apparent position shifts caused by GNSS antenna changes, GPS Solutions, No 13, p. 133-139.

Wübbena G., Menge F., Schmitz M., Seeber G., VölksenCh. (1997). A New Approach for Field Calibration of Absolute Antenna Phase Center Variations. Presented at ION GPS-96, Kansas City, Missouri.

Zhu S. Y., Massmann F. H., Yu Y., Reigber Ch. (2003). Satellite antenna phase center offsets and scale errors in GPS solutions. Journal of Geodesy, Vol. 77, No. 11-12, p. 668-672.

Received: 2011-04-13,

Reviewed: 2011-06-29, by W. Góral,

Accepted: 2011-07-21. 